\title{
AUDIT KINERJA GURU PADA SMP NEGERI 3 KATIBUNG DENGAN MENGGUNAKAN FRAMEWORK COBIT 4.1
}

\author{
Eni Setiawati \\ Fakultas Ilmu Komputer, Progam Studi Sistem Informasi \\ Institut Informatika dan Bisnis Darmajaya \\ Email: enisetiawati.1611059038P@mail.darmajaya.ac.id
}

\begin{abstract}
ABSTRAK
Penerapan kebijakan pada SMP NEGERI 3 KATIBUNG saat ini sudah dijalankan dengan baik. Hal ini terkadang membuat pihak sekolah ingin terus bergerak menjadi lebih baik, terutama dalam melaksanakan proses kegiatan belajar mengajar. Untuk mencapai hal tersebut dibutuhkannya pelaksanaan audit sebagai pengevaluasian kinerja-kinerja tersebut. Tujuan dari penelitian ini adalah mengevaluasi kinerja guru pada SMP NEGERI 3 KATIBUNG dan memberikan rekomendasi pada sekolah berdasarkan hasil analisa maturity level pada framework COBIT 4.1. Standar ini digunakan karena semua jenis aktivitas-aktivitas tersedia lengkap dan penggunaannya untuk orang awan mudah dimengerti dan diterapkan dengan baik. Penelitian ini menghasilkan temuan bahwa kinerja guru pada proses belajar mengajar pada pada SMP NEGERI 3 KATIBUNG dengan menggunakan framework COBIT 4.1 dengan domain DS3 \& DS4 berada di level 4 (managed and measurable). Hal ini menunjukkan bahwa kinerja guru pada proses belajar mengajar sudah diterapkan dengan baik. Prosedur dan kebijakan sudah dilakukan secara efektif dan terpantau. Serta tindakan perbaikan yang segera dilakukan.
\end{abstract}

Kata kunci: audit kinerja guru, kegiatan belajar mengajar, katibung, maturity level,COBIT 4.1

\section{PENDAHULUAN}

Sekolah merupakan sebuah institusi yang dirancang untuk belajar-mengajar. Proses pembelajaran dilakukan baik didalam kelas maupun diluar kelas. Dalam proses tersebut terdapat satu orang guru dengan puluhan siswa. Hal ini dapat diukur sebaik mana kinerja sekolah dalam mendidik dan mencerdaskan bangsa, khususnya guru sebagai tokoh utama tentunya.

SMP Negeri 3 Katibung berdiri pada tahun 2012 dengan jumlah ruang sebanyak 2 ruang kelas, 1 ruang guru, 1 Ruang kepala sekolah dan 1 Mushola, Tahun 2014 ditambah 2 ruang kelas dan 1 ruang perpustakaan, tahun 2015 ditambah lagi 2 ruang kelas dan 1 ruang laboratorium IPA. Pembangunan terus berlanjut hingga tahun pelajaran 2012/2013, kegiatan belajar mengajar mulai masuk pagi dengan jumlah penerimaan kelas yang tidak stabil disesuaikan dengan ruang kelas yang tersedia.

Kemudian pada tahun 2015 siswa siswi SMP Negeri 3 Katibung terdiri dari 6 kelas parallel yaitu kelas VII : 2 kelas, kelas VIII : 2 kelas, kelas IX : 2 kelas. Keadaan ini berlangsung sampai sekarang.
Pada penelitian ini, standar kontrol yang digunakan untuk audit pada sekolah menggunakan COBIT 4.1. Penulis menggunakan standar ini karena pada saat dilakukan audit semua jenis aktivitas-aktivitas tersedia lengkap dan penggunaannya untuk orang awan mudah dimengerti dan diterapkan dengan baik.

\section{METODELOGI AUDIT}

Pengumpulan data dilakukan untuk memperoleh informasi yang dibutuhkan dalam rangka mencapai tujuan penelitian. Tujuan yang diungkapkan dalam bentuk hipotesis merupakan jawaban sementara terhadap pertanyaan penelitian.metode pengumpulan data bisa dilakukan dengan cara :

1. Observasi

Mengamati langsung ke lapangan dan melakukan wawancara berkaitan dengan kinerja guru yang terjadi di SMP NEGERI 3 Katibung. Untuk melihat, mengetahui dan mendapatkan informasi tentang proses pembelajaran yang sedang berlangsung.

2. Studi Pustaka

Pada tahap ini dilakukan pengumpulan informasi-informasi yang berhubungan dengan 
tema yang di angkat dalam penelitian ini, dengan cara mengumpulkan buku-buku, literatur, katalog, Internet dan sumber-sumber lainya berkaitan dengan teknologi dan metode pencatatan kehadiran siswa agar didapatkan suatu metode absensi siswa yang lebih baik.

\section{HASIL DAN PEMBAHASAN}

\subsection{Gambaran Umum Responden}

Penetapan jumlah responden pada penelitian ini dengan membagi menjadi dua bagian, yakni: berdasarkan management dan user. Berikut tabel rekapitulasi daftar responden berdasarkan bagian yang dapat dilihat pada Tabel 1.

\section{Tabel 1. Rekapitulasi daftar responden berdasarkan bagian}

\begin{tabular}{|l|c|}
\hline \multicolumn{1}{|c|}{ Responden } & Jumlah Responden \\
\hline Management & 15 \\
\hline User & 23 \\
\hline Total & 38 \\
\hline
\end{tabular}

\subsection{Perhitungan Maturity Level}

Berdasarkan hasil perhitungan maturity level pada SMP NEGERI 3 KATIBUNG diketahui bahwa pada domain DS3 saat ini berada berada pada level 4 (Managed and Measurable). Sedangkan, pada domain DS4 saat ini berada pada level 4 (Managed and Measurable). Berikut spiderchart pada DS3 dan DS4 untuk management dapat dilihat pada Gambar 1.

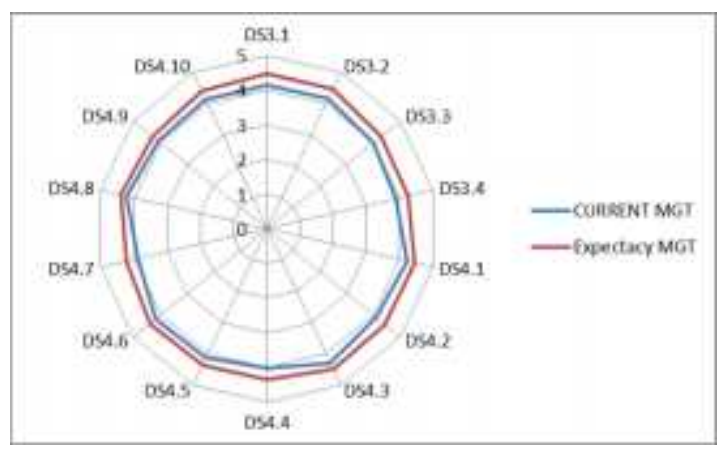

Gambar 1. Spiderchart DS3 dan DS4 Management

Dari hasil perhitungan maturity level pada SMP NEGERI 3 KATIBUNG diketahui bahwa pada domain DS3 user saat ini berada berada pada level 4 (Managed and Measurable). Sedangkan, pada domain DS4 user saat ini berada pada level 4 (Managed and
Measurable). Berikut spiderchart pada DS3 dan DS4 untuk user dapat dilihat pada Gambar 2.

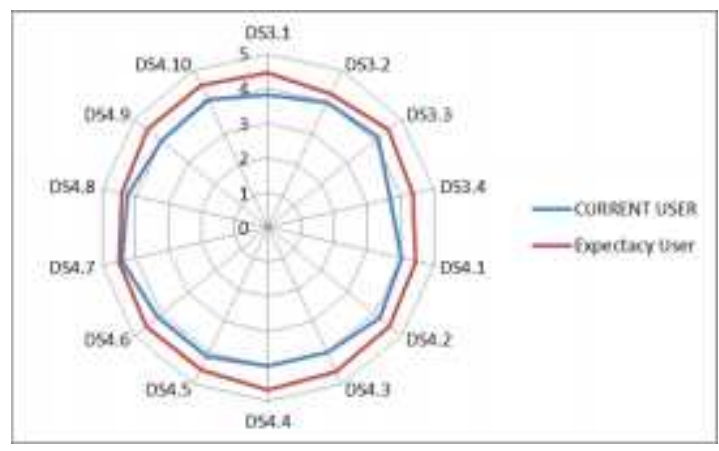

Gambar 2. Spiderchart DS3 dan DS4 User

Berdasarkan hasil perhitungan maturity level untuk management dan user pada domain DS3 dan DS4 didapatkan hasil akhir berupa grafik spiderchart yang dapat dilihat pada Gambar 3 .

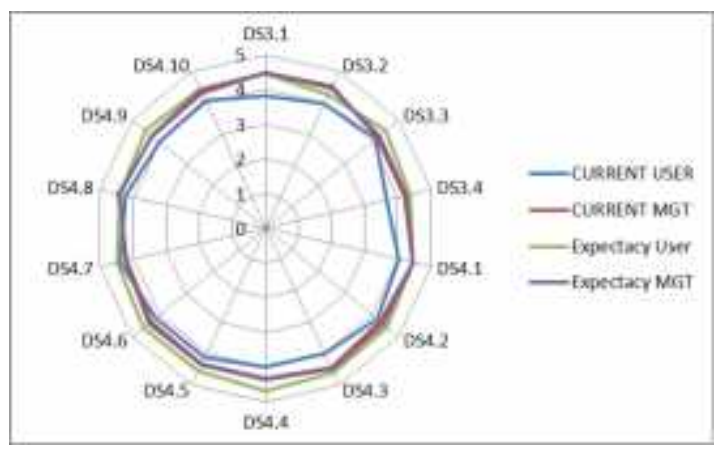

Gambar 3. Spiderchart DS3 dan DS4 SMP Negeri 3 Katibung

\subsection{Hasil GAP Analysis}

Setelah dilakukan perhitungan maturity level, hasil GAP yang diperoleh dari domain DS3 mendapat nilai 0,32 dimana nilai tersebut masih dalam level low dalam skala prioritas. Sedangkan, hasil GAP pada domain DS4 mendapat nilai 0,26 dimana nilai tersebut masih dalam level low dalam skala prioritas.

Sehingga, bila sekolah ingin menaikkan ke level 5-optimised. Maka sekolah harus menyediakan sumber daya IT yang memadai, melakukan monitoring dan membuat kebijakan mengenai penggunaan IT pada saat proses belajar mengajar.

\section{KESIMPULAN DAN SARAN}

\subsection{Kesimpulan}

Dari pembahasan sebelumnya, dapat disimpulkan bahwa: 
1. Indeks kematangan domain DS3 sebesar 4,05 dan berada pada level 4 (Managed and Measurable). Sedangkan, indeks kematangan domain DS4 sebesar 4,13 berada pada level 4 (Managed and Measurable).

2. Maturity activity terbesar berada pada domain DS4.3 sebesar 4,30. Sedangkan, maturity activity terkecil berada pada domain DS4.7 sebesar 3,90.

\subsection{Saran}

Adapun saran dari kesimpulan diatas, yakni : Sekolah disarankan untuk melakukan rekomendasi berdasarkan hasil dari perhitungan maturity level, khususnya bagian kinerja guru dalam proses belajar mengajar.

\section{DAFTAR PUSTAKA}

[1] A. S. Putra And O. M. Febriani, "Knowledge Management Online Application In Pdam Lampung Province," In Prosiding International Conference On Information Technology And Business (Icitb), 2018, Pp. 181-187.

[2] A. S. Putra, O. M. Febriani, And B. Bachry, "Implementasi Genetic Fuzzy System Untuk Mengidentifikasi Hasil Curian Kendaraan Bermotor Di Polda Lampung," $J$. Sist. Inf. Dan Manaj. Basis Data, Vol. 1, No. 1, Pp. 21-30, 2018.

[3] O. M. Febriani And A. S. Putra, "Sistem Informasi Monitoring Inventori Barang Pada Balai Riset Standardisasi Industri Bandar Lampung," J. Inform., Vol. 13, No. 1, Pp. 9098, 2014

[4] Putra, Arie Setya. "2018 Artikel Struktur Data, Audit Dan Jaringan Komputer." (2018).

[5] Putra, A. S., Sukri, H., \& Zuhri, K. Sistem Monitoring Realtime Jaringan Irigasi Desa (JIDES) Dengan Konsep Jaringan Sensor Nirkabel. IJEIS (Indonesian Journal of Electronics and Instrumentation Systems), 8(2), 221-232.

[6] Sari, D. P., Febriani, O. M., \& Putra, A. S. (2018, November). Perancangan Sistem Informasi SDM Berprestasi pada SD Global Surya. In Prosiding Seminar Nasional Darmajaya (Vol. 1, No. 1, pp. 289-294). 